\title{
ACTIVIDAD DEL TRIBUNAL CONSTITUCIONAL: RELACIÓN DE SENTENCIAS DICTADAS DURANTE EL PRIMER CUATRIMESTRE DE 2018
}

\section{Activity of the Constitutional Court: List of Rulings Handed \\ Down during the first Four-Month Period of 2018}

\author{
ÁREA DE DERECHO CONSTITUCIONAL \\ Universidad Carlos III de Madrid' \\ aelvira@der-pu.uc3m.es
}

Cómo citar/Citation

Elvira Perales, A. y Espinosa Díaz, A. (coords.) (2018). Actividad del Tribunal Constitucional: relación de sentencias dictadas durante el primer cuatrimestre de 2018 Revista Española de Derecho Constitucional, 113, 199-227. doi: https://doi.org/10.18042/cepc/redc.113.07

Las 47 sentencias dictadas en el primer cuatrimestre del año se desglosan de la siguiente forma:

A) Las sentencias dictadas en recursos de inconstitucionalidad son 17:

La Sentencia (STC) 2/2018, de 11 de enero, resuelve el recurso interpuesto por el presidente del Gobierno en relación con distintos preceptos de la Ley 7/2016, de 21 de julio, de medidas extraordinarias contra la exclusión social, de la Comunidad Autónoma de Extremadura. Como ocurriera en su STC 134/2017 (Comunidad Foral de Navarra), y posteriormente en su STC 145/2017 (Comunidad Valenciana), el Tribunal va a declarar inconstitucionales y nulos tales preceptos por regular un sistema de acceso a las prestaciones

\footnotetext{
1 La presente relación de sentencias ha sido elaborada por los profesores Elvira Perales y Espinosa Díaz (coords.); Pajares Montolío, Fraile Ortiz, Gómez Lugo y Baamonde Gómez.
} 
sanitarias que no atiende a los conceptos de asegurado o beneficiario que se establecen en la normativa básica estatal en la materia. El segundo ámbito recurrido es el que cuestiona el carácter inembargable de unas ayudas extraordinarias de apoyo social para contingencias recogidas en la norma autonómica. En aplicación de lo dicho en su STC 47/2004, declarará también inconstitucional y nulo dicho inciso, por invadir la competencia del Estado sobre legislación procesal, recogida en el art. 149.1.6 CE. La sentencia cuenta con dos votos particulares discrepantes, que reproducen lo alegado en otros tantos votos presentados a las SSTC 134/2017 y 145/2017 sobre el ámbito subjetivo de la atención sanitaria. El primero está firmado por los magistrados Fernando Valdés Dal-Ré, Juan Antonio Xiol Ríos, Cándido Conde-Pumpido Tourón y María Luisa Balaguer Callejón. El segundo lo firma el magistrado Antonio Narváez.

La STC 7/2018, de 25 de enero, resuelve el recurso interpuesto por más de cincuenta diputados del Grupo Parlamentario Popular en el Congreso en relación con diversos preceptos de la Ley del Parlamento de Cataluña 22/2010, de 20 de julio, del Código de consumo de Cataluńa. Los preceptos recurridos reconocen a los consumidores el derecho a ser atendidos de forma oral y escrita en la lengua oficial que escojan y a recibir determinada información en catalán. Los recurrentes alegaban que los preceptos en cuestión vulneraban los arts. 3, 9, 10, 14, 31.1, 38, 40.1, 139 y 149.1.1 CE, pero el TC solo considera suficientemente argumentada la referencia a los arts. 3, 38, 139.2 y 149.1.1 $\mathrm{CE}$, por lo que inadmite las restantes pretensiones. Una vez centrado el objeto del recurso, el Tribunal se va a remitir a la doctrina señalada al respecto en sus SSTC 31/2010 y 88/2017, que ya declaró la no inconstitucionalidad de algunos de ellos si se interpretan de conformidad con lo establecido en la sentencia. Por otro lado, va a desestimar los nuevos motivos de impugnación: no procede valorar la existencia de un conflicto competencial respecto del 149.1.1 CE por no haber aportado los recurrentes normativa estatal alguna que concrete las condiciones básicas que aseguren la igualdad cuya vulneración se denuncia. También desestima la alegada vulneración de la libertad de empresa del art. 38 CE y de la libertad de circulación y establecimiento de personas y bienes del art. 139.2 CE.

La STC 8/2018, de 25 de enero, resuelve el recurso interpuesto por el presidente del Gobierno en relación con diversos preceptos de la Ley del Parlamento vasco 6/2015, de 30 de junio, de medidas adicionales de protección medioambiental para la extracción de hidrocarburos no convencionales y la fractura hidráulica. Para resolver la cuestión constitucional, el Tribunal trae a su doctrina sobre el régimen del fracking desde la perspectiva competencial (SSTC 106/2014, 134/2014, 208/2014 y 73/2016). De este modo, recuerda 
que el art. 9.5 LSH es formal y materialmente básico al amparo del art.149.1.25 y $13 \mathrm{CE}$, ya que está dictado "con el objetivo de clarificar aspectos jurídicos relacionados con técnicas de exploración y producción de hidrocarburos y de garantizar la unidad de criterio en todo el territorio espańol». Asimismo, destaca que las comunidades autónomas no pueden prohibir de manera absoluta e incondicionada el empleo de la técnica de la fractura hidráulica al amparo de sus competencias en materia de sanidad (art.149.1.16 CE), de sus competencias estatutarias sobre ordenación del territorio (art.148.1.3 y art. 10.31 EAPV), ni de sus competencias para establecer «normas adicionales de protección» del medio ambiente (art.149.1.23 CE) (STC 8/2018, FJ 3). En aplicación de la doctrina anterior, el Tribunal declara la inconstitucionalidad del art. 3 por modificar el art. 28 de la Ley 2/2006, de Suelo y Urbanismo del País Vasco. En este sentido, señala que este precepto es prácticamente idéntico al art. 47.10 de la Ley de Urbanismo de Cataluña, anulado en la STC 73/2016 por los mismos motivos (FJ 4) y extiende esta conclusión a la disposición transitoria primera de la Ley 6/2015. Y, por último, declara inconstitucional el inciso «los hidratos de metano enterrados en el mar» del art. 2 de la Ley 6/2015 por vulnerar «la competencia del Estado sobre el subsuelo marino, que es la que determina que le corresponda a él otorgar las autorizaciones de exploración, permisos de investigación y concesiones de explotación en el mismo [artículo 3.2 b) LSH y STC 8/2013] así como ejercer las potestades administrativas de inspección sobre las actividades autorizadas en ese medio (arts. 31 y $32 \mathrm{LSH}$ )» (FJ 7). Formula un voto particular el Sr. Valdés, al que se adhieren el Sr. Conde-Pumpido y la Sra. Balaguer.

La STC 11/2018, de 8 de febrero, resuelve el recurso interpuesto por el presidente del Gobierno en relación con diversos preceptos de la Ley del Parlamento de Cataluña 35/2010, de 1 de octubre, del occitano, aranés en Arán. Dichos preceptos reconocen la condición de lengua de uso preferente del aranés respecto del castellano y del catalán, lo cual sería contrario a los apdos. uno y dos del art. 3 CE y al art. 6.2 del Estatuto de Autonomía de Cataluńa. Para encuadrar el proceso constitucional, el Tribunal acude al «sentido y finalidad de las normas impugnadas». De este modo, teniendo en cuenta que los preceptos impugnados se refieren al régimen de cooficialidad del aranés, resuelve la impugnación conforme a la doctrina constitucional en materia de cooficialidad lingüística, y en particular, en lo relativo al uso normal y uso preferente de una lengua cooficial. De acuerdo con dicha doctrina, el Tribunal ha formulado dos principios: a) la normalidad en el uso constituye un presupuesto de la oficialidad y una propiedad de la lengua que es oficial (SSTC 82/1986, FJ 2; 31/2010, FJ 4); b) la determinación de la preferencia en el uso de una lengua oficial respecto de otra (u otras) no es compatible con la Constitución. De esta 
doctrina constitucional se deriva que «la regulación de la cooficialidad lingüística no puede imponer la primacía de una de las lenguas oficiales en relación con otra, ni suponer una postergación o menoscabo de alguna de ellas. Por tanto, la cooficialidad ha de sujetarse a un patrón de equilibrio o igualdad entre lenguas, de forma que en ningún caso ha de otorgarse prevalencia o preponderancia de una lengua sobre otra» (FJ 4). Por ello, estima parcialmente y declara la inconstitucionalidad y nulidad de la palabra "preferente» del art. 2.3 a), el inciso «y debe otorgarle una posición preferente» del art. 5.4 y la palabra «preferentemente» de los arts. 5.7 y 6.5 de la Ley del Parlamento de Cataluńa 35/2010, de 1 de octubre, del occitano, aranés en Arán. Por el contrario, a juicio del Tribunal el art. 2.3. b) no merece reproche de inconstitucionalidad, siempre que se interprete de conformidad con lo expuesto en el FJ 5, en el sentido de que la declaración de uso normal del aranés no implica ni exclusión ni preferencia del aranés sobre las otras dos lenguas también oficiales en Arán, ni tampoco pretende privar al castellano y al catalán de esa cualidad de lenguas de uso normal en Arán [STC 86/2017, FJ 6 a)].

La STC 14/2018, de 20 de febrero, resuelve el recurso interpuesto por el Gobierno de la Generalitat de Cataluña en relación con diversos preceptos de la Ley Orgánica 8/2013, de 9 de diciembre, para la mejora de la calidad educativa, que da nueva redacción o añade preceptos de la Ley Orgánica 2/2006, de educación, y de la Ley Orgánica 8/1980, de 22 de septiembre, de Financiación de las Comunidades Autónomas (LOFCA). Buena parte de los artículos recurridos son declarados constitucionales por considerar el Tribunal que son parte de la competencia estatal que, de conformidad con el art. 149.1.30. ${ }^{a} \mathrm{CE}$, tiene el Estado. También considera carente de reproche constitucional los limitados plazos que tenían las comunidades autónomas para desarrollar sus normativas, pues no se ha probado una imposibilidad material. El Tribunal sí declara inconstitucional la disposición final séptima bis LOE, añadida por el artículo único 109 LOMCE, por carecer de criterios para realizar el desarrollo reglamentario básico. Ahora bien, tal declaración de inconstitucionalidad no afectará, por seguridad jurídica, a los actos firmes dictados en su aplicación. También se declara inconstitucional la disposición adicional 38.4c), párrs. 3 , 4 y 5 porque no respeta los límites establecidos por el Tribunal en relación con la Alta Inspección de Educación, yendo las funciones atribuidas más allá de las de comprobación, verificación o fiscalización que debe cumplir. Esta declaración lleva aparejada la declaración de inconstitucionalidad de la disposición final 5..$^{\mathrm{L}} \mathrm{LOE}$ y la disposición adicional 8. a apdo. 3. $\mathrm{LO} 8 / 1980$, por la conexión con estas normas.

La STC 16/2018, de 22 de febrero, resuelve el recurso interpuesto por el presidente del Gobierno en relación con diversos preceptos de la Ley Foral 
24/2013, de 2 de julio, de medidas urgentes para garantizar el derecho a la vivienda en Navarra. Se declara inconstitucional la DA décima en sus apdo. $1 .^{\circ}$ y $2 .^{\circ}$, por entender que el ejercicio que en ellos se hacía de la competencia de vivienda interfiere en la competencia estatal del 14.1.13, tal y como se pronunció ya este Tribunal en la STC 93/2015 en relación con una ley andaluza de contenido similar. Se desestima en todo lo demás.

La STC 17/2018, de 22 de febrero, resuelve el recurso interpuesto por el presidente del Gobierno en relación con la Ley Foral 8/2013, de 25 de febrero, por la que se reconoce a las personas residentes en Navarra el derecho de acceso a la asistencia sanitaria gratuita del sistema público sanitario de Navarra. En torno al alcance de las normas estatales básicas en el ámbito subjetivo del derecho de acceso a las prestaciones sanitarias, el asunto es similar al resuelto en las SSTC 134/2017, 145/2017 y 2/2018, y con respecto a las prestaciones farmacéuticas complementarias al que fue objeto de la STC 140/2017. Los votos particulares —uno formulado por los Sres. Valdés dal Ré, Xiol Ríos, Conde-Pumpido y la Sra. Balaguer, y otro por el Sr. Narváez- discrepan sobre el alcance en el ámbito subjetivo de las normas estatales básicas, lo que determinaría la validez de las normas autonómicas

La STC 19/2018, de 22 de febrero, resuelve el recurso interpuesto por más de cincuenta diputados del Grupo Parlamentario Socialista del Congreso en relación con diversos preceptos de la Ley 21/2014, de 4 de noviembre, por la que se modifica el texto refundido de la Ley de Propiedad Intelectual, y con un crédito presupuestario incluido en la Ley 36/2014, de 26 de diciembre, de Presupuestos Generales del Estado para 2015. Inicia el Tribunal la delimitación del objeto, señalando la modificación legislativa posterior, con ocasión del Real Decreto Ley 12/2017, de 3 de julio, en materia de compensación equitativa por copia privada; así como la STJUE de 9 de junio de 2016, que declaró el sistema ahora impugnado como contrario al art. 5.2 b) de la Directiva 2001/29/CE del Parlamento Europeo y del Consejo, relativa a la armonización de determinados aspectos de los derechos de autor y derecho afines a los derechos de autor en la sociedad de la información (con la consecuencia de su no aplicación práctica), quedando así advertida la pérdida sobrevenida de objeto respecto de buena parte de las impugnaciones formuladas por los recurrentes. Procede en consecuencia el pronunciamiento del Tribunal acerca de la constitucionalidad de los preceptos cuestionados en relación el régimen de «ventanilla única» (gestionado por una persona jurídica diferente de las entidades de gestión), considerados por los recurrentes contrarios al derecho de asociación (art. 22 CE). Consideración que no comparte el Tribunal, al entender que la debida creación de una persona jurídica diferente no necesariamente impone la creación de una figura de índole asociativa, no resultando 
así afectado el derecho del art. 22 CE. Se concluye así con la desestimación del recurso respecto de todos aquellos aspectos que no habían quedado incluidos en la pérdida sobrevenida de objeto.

La STC 28/2018, de 8 de marzo, resuelve el recurso interpuesto por el presidente del Gobierno en relación con diversos preceptos de la Ley 1/2006, de 19 de abril, del sector audiovisual de la Comunidad Valenciana. En ella se declara la pérdida sobrevenida de objeto por desaparición de la actividad regulada (emisiones analógicas). Las cuestiones fueron en su mayor parte resueltas por la STC 78/2017, interpretando con respecto al gestor del múltiple digital que las obligaciones, la forma, la composición y el funcionamiento de este gestor las tiene que fijar al Estado ex art. 149.1.21. ${ }^{a} \mathrm{CE}$.

La STC 29/2018, de 8 de marzo, resuelve el recurso interpuesto por el presidente del Gobierno respecto del art. 83 de la Ley del Parlamento Vasco 1/2016, de 7 de abril, de atención integral de adicciones y drogodependencias. El Tribunal resuelve el recurso interpuesto acudiendo a la doctrina sentada en la STC 144/2017 en un asunto semejante desde el punto de vista del contenido de la norma recurrida y de las alegaciones de las partes, y que cuestiona el alcance de las competencias estatal y autonómica sobre sanidad, legislación penal y seguridad pública. En el fallo, el TC declarará la no inconstitucionalidad del precepto «siempre que se interprete que, sin predeterminar el tipo de asociación que son las entidades de personas consumidoras de cannabis, se limita a prever que deben cumplir ciertas funciones de colaboración con la Administración sanitaria».

La STC 31/2018, de 10 de abril resuelve el recurso interpuesto por más de cincuenta diputados del Grupo Parlamentario Socialista en el Congreso en relación con diversos preceptos de la Ley Orgánica 8/2013, de 9 de diciembre, para la mejora de la calidad educativa. El Tribunal, tras inadmitir la solicitud de adhesión del Parlamento de Navarra y hacer un breve excurso acerca de la finalidad de la LOMCE y sus principios inspiradores, así como un esquema de su doctrina reiterada sobre el art. $27 \mathrm{CE}$, comienza a analizar las diversas denuncias de inconstitucionalidad señaladas por los recurrentes, y que pueden articularse en cuatro ejes temáticos:

- Acerca de la enseñanza diferenciada por sexos: se pone en duda la constitucionalidad de un modelo educativo consistente en la aplicación de un sistema que diferencia por sexos, y asimismo se cuestiona la imposibilidad legal de denegar por parte de las administraciones educativas el concierto a aquellos centros docentes que desarrollan este tipo de educación. Considera, sin embargo, el Tribunal que dicha separación no responde a un programa filosófico, moral o ideológico, 
sino que tiene carácter meramente instrumental (elemento pedagógico). Acudiendo al derecho internacional en la materia, en virtud de la cláusula del art. 10.2 CE, se citan como parámetro de referencia el art. 2 de la Convención relativa a la lucha contra las discriminaciones de la UNESCO de 1960 (aludido en el propio texto legislativo), el Pacto Internacional de Derechos Económicos, Sociales y Culturales de 1966 y la Convención sobre la Eliminación de todas las Formas de Discriminación contra la Mujer de 1979, concluyendo que la segregación por sexos no resulta discriminatoria siempre que se cumpla con la exigencia de la «equivalencia» en el acceso de los alumnos y alumnas a la enseñanza, en las condiciones de la prestación y en los contenidos docentes. Resaltando, además, la obligación de fomento dispuesta por la propia LOMCE, que requiere a los centros docentes que utilicen este método pedagógico para exponer en su proyecto educativo "las medidas académicas que desarrollan para favorecer la igualdad». Se alude asimismo a la realidad educativa de otros países como Gran Bretaña, Francia, Alemania, Bélgica o Estados Unidos. Acudiendo a la doctrina del propio Tribunal sobre la prohibición de discriminación del art. $14 \mathrm{CE}$ - en concreto, cuando el trato diferenciado obedece a una de las «categorías sospechosas» y requiere de un test ponderativo más riguroso-, el Tribunal enmarca la educación segregada dentro del ideario educativo propio de cada centro (punto de convergencia entre el derecho de creación de centros y el derecho de los padres a elegir el tipo de educación que desean para sus hijos), no considerando que transgreda los límites constitucionales por cumplirse con el mencionado requisito de la «equiparabilidad». Por lo que respecta a la pretensión subsidiaria de los recurrentes acerca del concierto, argumenta su compatibilidad constitucional, y va más allá, justificando el blindaje legal en el respeto al principio de igualdad en el reparto de ayudas públicas.

- Vulneraciones relativas al derecho de los profesores, padres y alumnos a intervenir en el control y gestión de los centros sostenidos con fondos públicos (art. 27.7 CE): concretamente se denuncia el nuevo rol del Consejo Escolar tras la reforma, al pasar a tener una función de mero informe y propuesta, sin capacidad de codecisión ni corresponsabilidad alguna con el titular del centro o su director. El Tribunal inicia su argumentación repasando su doctrina previa en relación con el derecho de participación en el ámbito educativo, orientada a trazar un equilibrio entre este y los derechos que asisten al titular y/o a la dirección del centro, destacando en todo caso, el amplio margen de 
configuración que asiste al legislador en la materia, concluyendo finalmente que las nuevas atribuciones, si bien reducen el nivel de intervención, no presentan tacha de inconstitucionalidad, pues no afectan al contenido esencial del derecho de participación.

- Sobre la implantación de un nuevo sistema para la enseñanza de las asignaturas de religión y valores culturales y cívicos/valores éticos: el cuestionamiento se centra en la equiparación material de las asignaturas, lo que supone, a juicio de los recurrentes, una fusión indebida de planos y una discriminación para los alumnos que escogen la materia confesional y no pueden cursar la alternativa de valores éticos y ciudadanos. El Tribunal, tras un sumario recorrido por su jurisprudencia previa acerca del art. $16 \mathrm{CE}$, determina que la existencia de una asignatura evaluable de religión de carácter voluntario no conlleva objeción constitucional alguna, y que tampoco se acredita la discriminación denunciada, en la medida en que la propia LOMCE, a pesar de la alternatividad, permite que, en función de la regulación y la programación de la oferta educativa, el alumnado pueda cursar simultáneamente ambas disciplinas.

— La separación del alumnado por itinerarios en la Educación Secundaria Obligatoria (ESO), la remisión al Gobierno para la regulación del programa de mejora del aprendizaje y del rendimiento, las causas para la derivación hacia la Formación Profesional y la participación del alumnado en las decisiones que afecten a su currículum también son objeto de recurso. En particular, se plantea si la regulación de tales aspectos respeta las reservas de ley orgánica y ley ordinaria que rigen como garantías normativas del derecho fundamental a la educación. El Tribunal, tras repasar su doctrina previa acerca de las reservas normativas y la colaboración del reglamento en desarrollo de los derechos fundamentales, llega a la conclusión de que no cabe imputar a los preceptos impugnados la falta de densidad normativa alegada por la parte recurrente.

— Finalmente, los recurrentes consideran contrarios a la Constitución los preceptos que permiten a los centros docentes (públicos y privados concertados) realizar la admisión de alumnos introduciendo el factor «rendimiento escolar», con una ponderación de hasta un máximo de un $20 \%$ de la puntuación asignada a las enseñanzas posobligatorias en aquellos centros que tengan reconocida una especialización curricular o que participen en una acción destinada a fomentar la calidad de dichos centros. Concluye el Tribunal negando que las disposiciones concernidas sean vulneradoras de reserva de ley orgánica u 
ordinaria, así como tampoco considera que se haya producido una invasión de la competencia pública de programación general de la enseñanza (art. 27.5 CE) por la atribución a los centros docentes de la posibilidad de valorar el rendimiento académico en la admisión.

La sentencia cuenta con varios votos particulares: el primero, concurrente, de la vicepresidenta Sra. Roca Trías, discrepante con la fundamentación, particularmente en el punto en que la sentencia mayoritaria parece sugerir que existe una "obligación constitucional» de financiar a través del concierto a los centros que practican la educación segregada por sexos, en la medida en que no se considera una opción discriminatoria, conclusión no compartida por limitar el legítimo margen de configuración del legislador democrático.

El segundo voto discrepante, del Sr. Valdés Dal Ré, al que se adhiere el Sr. Conde-Pumpido, articula la disensión en tres puntos: 1) considera vedada la educación segregada por razón de sexo en virtud de los arts. 1, 9.2, 14, 27.2 CE; 2) enseńanza religiosa versus enseñanza de valores culturales y cívicos/ valores éticos, cuestionado aquí la alternatividad entre el ideario confesional y el ideario constitucional para concluir con su incompatibilidad con el mandato constitucional de neutralidad religiosa del Estado; 3) en torno al derecho de los menores a participar en las decisiones relativas a sus itinerarios educativos, la discrepancia es de carácter argumentativo.

En tercer lugar, es igualmente discrepante el voto del Sr. Xiol Ríos, cuya exposición se divide en dos bloques temáticos:

a) Con respecto a la segregación sexual binaria abunda en elementos ya planteados en los dos votos anteriores y, a su vez, hace hincapié en la oportunidad perdida por el Tribunal de abordar el caso como un «caso líder» en materia de derecho antidiscriminatorio, insiste en la necesidad de una lectura evolutiva de los derechos y la superación del lema «separados pero iguales», y, muy especialmente, destaca la naturaleza excluyente de la medida con las personas intersexuales (no reconducibles a los estándares culturales femenino y masculino).

b) En relación con la regulación de la asignatura de religión, considera que vulnera el principio constitucional de aconfesionalidad del Estado.

Finalmente, formula otro voto particular discrepante la Sra. Balaguer, en línea con los dos votos precedentes.

La STC 32/2018, de 12 de abril resuelve el recurso interpuesto por el presidente del Gobierno respecto del art. 1 y la disposición adicional primera de la Ley del Parlamento de Andalucía 4/2013, de 1 de octubre, de medidas 
para asegurar el cumplimiento de la función social de la vivienda. Con base en las SSTC 93/2015 y 16/2018 considera inconstitucional la disposición adicional primera de la ley por interferir de modo significativo en el uso de las competencias estatales derivadas del art. 149.1.13. ${ }^{\circ}$ CE. Se realiza también una interpretación conforme del art. 1.3 de la ley, en la que se establecía el deber de destinar la vivienda a la habitación como parte del contenido esencial, y se dice que no debía entenderse como un real deber del propietario, sino como un fin a perseguir por los poderes públicos y, por tanto, no invadiría las competencias estatales.

La STC 33/2018, de 12 de abril, resuelve el recurso interpuesto por el Gobierno de la Generalitat de Cataluña en relación con diversos preceptos de la Ley 15/2014, de 16 de septiembre, de racionalización del sector público y otras medidas de reforma administrativa. El fallo estima parcialmente y determina la compatibilidad de algunos de los preceptos impugnados a través de la interpretación conforme. Comienza el Tribunal aclarando que durante la pendencia del procedimiento la Ley 30/1992 fue derogada por la nueva Ley 39/2015, de 1 de octubre, del procedimiento administrativo común de las administraciones públicas. Se rechaza, sin embargo, que pueda darse un supuesto de pérdida sobrevenida del objeto, en la medida en que con la nueva regulación subsiste la controversia referida en el recurso. Por lo que respecta al fondo del asunto:

- Acerca de la «licencia deportiva única»: se plantea un conflicto estrictamente competencial. De acuerdo con el marco constitucional y estatutario (arts. 148.1.19 CE y 134 Estatuto de Autonomía de Cataluña), y con apoyo en las SSTC 80 y 110/2012, la materia deporte es una competencia exclusiva de la comunidad catalana, si bien debe ser ejercida dentro de los siguientes límites: respeto a las competencias que puedan corresponder al Estado en virtud de otros títulos competenciales (supuestos de actuación supraautonómica) y de acuerdo con el principio de territorialidad de las competencias. Considera el Tribunal que la regulación del Estado se enmarca en la materia deporte, en la que este ostenta competencias exclusivamente sobre los «intereses generales del deporte español en su conjunto». En relación con los efectos concretos de la llamada «licencia única», el Estado estaría facultado para dar un efecto «vertical» a una licencia deportiva autonómica (habilitando a su titular para participar en competiciones oficiales de ámbito estatal); no así, sin embargo, efectos «horizontales» o «transversales» (habilitando a la participación en competiciones oficiales de ámbito territorial inferior), pues, en este último caso, el 
Estado estaría incidiendo en intereses estrictamente autonómicos y, en consecuencia, perturbando el ejercicio de sus competencias. De acuerdo con esos argumentos, se determina la inconstitucionalidad respecto del efecto transversal u horizontal; en cuanto al de tipo vertical, se impone la interpretación conforme a la norma, y se descartan extralimitaciones competenciales en todo lo demás (art. 23).

- Por lo que respecta a la implantación del «tablón edictal único» a través del $\mathrm{BOE}$ : el amparo competencial se encuentra en el art. 149.1.18 $\mathrm{CE}$, concretamente en la dimensión de «bases del régimen jurídico de las Administraciones Públicas» (garantía de un tratamiento común de los ciudadanos ante las diferentes administraciones), no apreciándose una invasión competencial en este punto.

- En cuanto a la regulación de la base de datos nacional de subvenciones: el Estado goza de competencias para instituir un sistema nacional de publicidad de las subvenciones (principios de publicidad y transparencia) en virtud del art. 149.1.18 CE. Se cuestiona, sin embargo, la intermediación de este órgano ante la exigencia de «dar traslado de un extracto de la convocatoria al diario oficial correspondiente para su publicación", entendiendo el Tribunal que procede declarar su inconstitucionalidad (los incisos "por conducto de la base de datos nacional de subvenciones» $\mathrm{y}$ "la base de datos nacional de subvenciones dará traslado al diario oficial correspondiente del extracto de la convocatoria, para su publicación, que tendrá carácter gratuito» del art. 30), por suponer una perturbación en la actuación de la Administración autonómica (la intermediación, no así la exigencia de comunicación, que no presenta óbice constitucional). Asimismo, se pronuncia el órgano acerca de la compatibilidad constitucional de las previsiones de multas coercitivas para el caso de incumplimiento del debido suministro de información: tras realizar un análisis de la capacidad de supervisión del Estado y el equilibrio con el derecho a la autonomía, concluye que estas sitúan a las comunidades autónomas en una posición de subordinación inadmisible de acuerdo con la autonomía constitucionalmente garantizada, imponiendo la interpretación conforme de los preceptos afectados (art. 30.7 y 9) y excluyendo la referencia a las comunidades autónomas.

La STC 40/2018, de 26 de abril, resuelve el recurso interpuesto por el presidente de Gobierno respecto de los arts. 15 y 16 de la Ley Foral 14/2007, de 4 de abril, del Patrimonio de Navarra. Se trata de una controversia competencial, los preceptos objeto de diferencia se inscriben en la materia «formas de 
adquirir la propiedad» y el fondo de la cuestión reside en la determinación del alcance de la competencia para el «desarrollo» del derecho civil foral. Con base en las SSTC 88/1993, 31/2010 y 95/2017, el elemento clave es la identificación de una "conexión» con aquel derecho, y a partir de la evolución normativa en materia de bienes inmuebles vacantes y depósitos y saldos abandonados efectuado por las SSTC 58/1982 y 204/2004 y las alegaciones históricas formuladas por los letrados del Gobierno y el Parlamento de Navarra, queda acreditada la conexión de la regulación cuestionada con el particular derecho civil foral. Formula un voto particular el magistrado Pedro González-Trevijano, al que se adhieren Andrés Ollero, Antonio Narváez, Alfredo Montoya y Ricardo Enríquez, discrepante con la argumentación y el fallo, por los motivos ya expuestos en su voto a la STC 41/2018.

La STC 41/2018, de 26 de abril, resuelve el recurso interpuesto por el presidente de Gobierno en relación con la disposición adicional sexta de la Ley 5/2011, de 10 de marzo, del Patrimonio de Aragón, y la disposición adicional sexta del texto refundido de la Ley de Patrimonio de Aragón, aprobado por Decreto Legislativo 4/2013, de 17 de diciembre. En ella se dilucidan las competencias estatales sobre legislación civil (art. 149.1.8. ${ }^{a}$ CE) y autonómica sobre reglas de conservación, modificación y desarrollo del derecho foral aragonés (art. 71.2 EAAra), en relación con la regulación del destino de las fincas procedentes de procesos de concentración parcelaria que carezcan de dueño conocido. El desarrollo del derecho foral permite al legislador autonómico regular una institución antes no contemplada en él, si tiene como punto de partida una institución conexa preexistente en ese derecho civil especial, lo cual, en este caso, conforme a la STC 40/2018, se podría identificar con la sucesión abintestato. Formula un voto particular discrepante el Sr. González-Trevijano, al que se adhieren los Sres. Ollero Tassara, Narváez Rodríguez, Montoya Melgar y Enríquez Sancho, por no apreciar la conexión.

La STC 42/2018, de 26 de abril, resuelve el recurso interpuesto por más de cincuenta diputados del Grupo Parlamentario Unidos Podemos-En Comú Podem-En Marea en el Congreso de los Diputados en relación con diversos preceptos de la Ley del Parlamento de Canarias 2/2016, de 27 de septiembre, para la modificación de la Ley 6/2002, de 12 de junio, sobre medidas de ordenación territorial de la actividad turística en las islas de El Hierro, La Gomera y La Palma. El Tribunal considera inconstitucional y nula únicamente la disposición legal autonómica que declara determinadas actuaciones de interés insular a efectos de la tramitación de instrumentos de planificación singular turística, reiterando para ello lo señalado, entre otras, en la STC 129/2013: a juicio del Tribunal la norma reviste el aspecto de ley singular, pero no justifica el supuesto de hecho ni es proporcionada a la excepcionalidad que trata de 
atender. A ello hay que añadir que incide en el derecho a la tutela judicial efectiva al impedir el acceso al control judicial de derechos e intereses legítimos afectados y eliminar la posibilidad de un control judicial de la misma intensidad que hubieran podido realizar los tribunales de la jurisdicción contencioso-administrativa.

La STC 43/2018, de 26 de abril, resuelve el recurso interpuesto por el presidente del Gobierno respecto de diversos preceptos de la Ley 2/2014, de 20 de junio, de modificación de la Ley $2 / 2003$, de 30 de enero, de vivienda de Canarias y de medidas para garantizar el derecho a la vivienda. Reproduce la doctrina sentada en las recientes SSTC 16/2018 y 32/2018, que enjuiciaban leyes con contenidos similares, y hace interpretación conforme del art. 1.1 de la Ley 2/2014 e inconstitucionales los artículos 1.6, 1.7 y DA cuarta de la Ley 2/2014.

B) Las sentencias dictadas en cuestiones de inconstitucionalidad han sido 2:

La STC 1/2018, de 11 de enero, resuelve la cuestión planteada por la Sala de lo Civil y Penal del Tribunal Superior de Justicia de Cataluña con respecto al art. 76 e) de la Ley 50/1980, de 8 de octubre, de Contrato de Seguro. El precepto cuestionado dispone que el «asegurado tendrá derecho a someter a arbitraje cualquier diferencia que pueda surgir entre él y el asegurador sobre el contrato de seguro", y es transposición de la norma anteriormente recogida en el art. 6 de la Directiva 87/344/CEE, transpuesta también en la citada Ley 21/1990, y que actualmente se mantiene en el art. 203 de la Directiva 2009/138/ CEE. Según el órgano proponente la norma cuestionada, al someter a arbitraje los conflictos surgidos entre asegurador y asegurado en el seguro de defensa jurídica, siempre que tal sea la voluntad expresada por el asegurado, constituye una vulneración del derecho a la tutela judicial efectiva del asegurador, en relación con el principio de exclusividad jurisdiccional establecido por el art. 117.3 CE.

Para dilucidar la cuestión de si la regulación del arbitraje que deriva del precepto cuestionado es conforme con dichas norma constitucionales, el Tribunal trae a colación su doctrina sobre el arbitraje como medio de solución extrajudicial de conflictos, así como sobre el denominado «arbitraje obligatorio», en relación con el art. $24 \mathrm{CE}$. La sentencia recuerda que «el arbitraje en cuanto equivalente jurisdiccional, se sustenta, en la autonomía de la voluntad de las partes plasmada en el convenio arbitral». El Tribunal considera que un arbitraje obligatorio para una de las partes en la controversia resultaría plenamente compatible con el art. 24.1 CE si en ningún caso excluye el ulterior conocimiento jurisdiccional de la cuestión y su fin resulta proporcionado y justificado, a la vez que considera que el derecho reconocido al asegurado por 
el art. 76 e) LCS y la correlativa obligación del asegurador de someterse a dicho arbitraje debe cohonestarse con las exigencias del derecho fundamental a la tutela judicial efectiva, tal como ya se señaló en la citada STC 119/2014. En consecuencia, el Tribunal concluye que la imposición de un arbitraje como el previsto en el artículo 76 e) LCS vulnera el derecho a la tutela judicial efectiva garantizado en el artículo $24 \mathrm{CE}$, pues impide el acceso a la jurisdicción de los juzgados y tribunales de justicia que, ante la falta de la voluntad concurrente de los litigantes, son los únicos que tienen encomendada constitucionalmente la función de juzgar y hacer ejecutar lo juzgado (art. $117 \mathrm{CE}$ ). La cuestión de inconstitucionalidad es estimada y, en consecuencia, se declara inconstitucional y nula la norma impugnada. Se formulan tres votos particulares: uno formulado por el magistrado Fernando Valdés, otro por el magistrado Juan Antonio Xiol, y el tercero por el magistrado don Antonio Narváez, al que se adhiere el magistrado Ricardo Enríquez.

La STC 45/2018, de 26 de abril, resuelve la cuestión planteada por la Sala de lo Contencioso-Administrativo de la Audiencia Nacional respecto de la disposición adicional cuadragésima cuarta de la Ley 39/2010, de 22 de diciembre, de Presupuestos Generales del Estado para 2011. La norma, cuya constitucionalidad se cuestiona, podría comprometer, a juicio de la Sala de lo C-A de la Audiencia Nacional, el art. $33 \mathrm{CE}$ al no concurrir causa de utilidad pública o interés social en la privación del derecho a una pensión adquirido a partir de lo previsto en una norma con rango de ley por quien litiga ante su sede, y también el art. 9.3 CE, pues la norma en cuestión incurre en retroactividad de grado máximo al retrotraer sus efectos al 18 de febrero de 2010, lo que comporta la exigencia de devolución de las cantidades devengadas, cobradas y consumidas a la fecha de su entrada en vigor (la pensión excepcional de viudedad reconocida a la recurrente lo fue por el Real Decreto-ley 8/2004). El Tribunal Constitucional analiza la naturaleza jurídica de la norma cuestionada, y concluye que se trata de una ley singular que adopta una medida expropiatoria: al constatar, en la línea de lo argumentado por el órgano a quo y por el FGE, que no concurre la finalidad de utilidad pública o interés social que ha de legitimar cualquier medida de naturaleza expropiatoria, declara inconstitucional y nula la norma impugnada por vulnerar el art. $33 \mathrm{CE}$, lo que lleva a no considerar necesario pronunciarse sobre la alegada vulneración del art. 9.3 CE.

C) Se pronuncia una cuestión prejudicial de validez sobre normas forales fiscales:

La STC 13/2018, de 13 de febrero, resuelve la cuestión planteada por la Sección Primera de la Sala de lo Contencioso-Administrativo del Tribunal 
Superior de Justicia del País Vasco en relación con el art. 4.2 de la Norma Foral de Gipuzkoa 13/2012, de 27 de diciembre, por la que se aprueban determinadas modificaciones tributarias. La norma impugnada eliminaba la exención del impuesto de transmisiones jurídicas patrimoniales y actos jurídicos documentados en favor de las iglesias y confesiones con acuerdo, prevista concretamente en la Ley 26/1992 (para la comunidad islámica). A juicio del Tribunal, tal previsión afecta a las condiciones básicas en el ejercicio del derecho fundamental a la libertad religiosa y por tanto vulnera 149.1.1 CE, en relación con el 16.3 CE y 7 LOLR.

D) Las sentencia dictadas en conflictos positivos de competencia son 3:

La STC 15/2018, de 22 de febrero, resuelve el conflicto planteado por el Gobierno de la Generalitat de Cataluña en relación con el Real Decreto 1494/2011, de 24 de octubre, por el que se regula el fondo de carbono para una economía sostenible. Las competencias controvertidas son: las competencias estatales sobre legislación básica de medio ambiente (art. 149.1.23. ${ }^{\mathrm{a}} \mathrm{CE}$ ) y sobre bases y coordinación de la planificación general de la actividad económica (art. 149.1.13 a $\mathrm{CE}$ ), y competencias autonómicas sobre medio ambiente (art. 144.1 EACat) y de fomento en materias de competencia compartida (art. 114.3 EACat) en relación con el fondo de carbono para una economía sostenible y la regulación de la adquisición de créditos de carbono derivada de proyectos desarrollados en Espańa. Por otra parte, en cuanto a las funciones de los órganos rectores del fondo: a) determinar las prioridades del fondo no es una actividad que tenga carácter normativo, sino ejecutivo, de modo que su regulación tiende a enmarcar el amplio margen de discrecionalidad del que goza el Consejo Rector; b) la capacidad de los proyectos para promover actividad económica hipocarbónica rebasa el ámbito territorial de una comunidad autónoma, por lo que cabe aplicar el criterio de supraterritorialidad que excepcionalmente permite justificar que el Estado se reserve competencias de carácter ejecutivo en estas materias: conseguir los objetivos del fondo requiere que todos los proyectos que en Espańa puedan optar a la venta de créditos de carbono concurran en un proceso de valoración que garantice la correcta aplicación de los criterios que rigen esta actividad, por lo que, para ser homogénea, ha de realizarse por un solo órgano. Partiendo de lo anterior, en torno a la composición y participación de las comunidades autónomas en los órganos rectores del fondo: a) dado que el ejercicio de las competencias del fondo no se puede fragmentar a través de su territorialización y la adquisición por las comunidades autónomas de reducciones verificadas de emisiones de gases de efecto invernadero, lo que impide a estas asumir competencias en esta gestión; 
b) las previsiones sobre colaboración con las comunidades autónomas son insuficientes (integración de un solo representante de todas las comunidades autónomas en el consejo rector), pues no se arbitra ningún mecanismo concreto que sirva a los efectos de garantizar que sus diversas posiciones sean consideradas por el Estado al establecer las directrices del fondo para la compra de créditos de carbono, los criterios y requisitos de selección de las reducciones verificadas de emisiones o en la selección de proyectos. Finalmente, se analiza la acreditación de verificadores medioambientales en el marco del sistema de gestión y auditoría medioambientales, apreciando aquí que la función de carácter ejecutivo solo podría ostentarla el Estado con carácter excepcional, pues no se aprecia que para este supuesto no sea posible el fraccionamiento de la actividad pública y por ello requiera un grado de homogeneidad que solo pueda garantizar su atribución a un único titular (STC 33/2005). Con base en los argumentos anteriores el fallo es parcialmente estimatorio.

La STC 18/2018, de 22 de febrero, resuelve el conflicto planteado por el Gobierno de la Nación respecto del Decreto Foral 117/2012, de 31 de octubre, por el que se modifica el Decreto Foral 640/1996, de 18 de noviembre, que establece el procedimiento y las condiciones para el acceso a las prestaciones del régimen de universalización de la asistencia sanitaria pública en la Comunidad Foral de Navarra. En ella se declara la pérdida parcial de objeto y la estimación de todo lo demás, de manera similar a como hiciera en la STC 134/2017. Se formulan dos votos particulares coincidiendo sus firmantes con los de la STC 17/2018.

La STC 30/2018, de 22 de marzo, resuelve el conflicto planteado por el Gobierno de la Generalitat de Cataluña respecto del Real Decreto 591/2014, de 11 de julio, por el que se regulan los procedimientos relativos al reconocimiento de la compensación de los costes de escolarización previstos en el apdo. cuarto de la disposición adicional trigésimo octava de la Ley Orgánica 2/2006, de 3 de mayo, de Educación. Recuerda el Tribunal su anterior STC $14 / 2018$, en la que declaró la inconstitucionalidad y nulidad de aquellos preceptos de la LOE, en la redacción introducida por la LOMCE, que se encuentran explícitamente desarrollados por la norma ahora impugnada. Tratándose de la misma controversia jurídica, se remite a la doctrina sentada en la referida resolución, determinando así la estimación del conflicto positivo de competencia y, en consecuencia, la declaración de inconstitucionalidad y nulidad del real decreto objeto de impugnación, no sin antes limitar el alcance temporal de tal declaración (en atención al principio de seguridad jurídica, art. 9.3 CE, así como a la garantía del derecho a la educación, art. $27 \mathrm{CE}$ en conexión con el art. 87.4 LOE), reconociendo la garantía de continuidad en la escolarización hasta el final de la enseñanza obligatoria de los alumnos que hayan sido 
escolarizados mediante este procedimiento (salvo que se efectúe un cambio de centro por voluntad familiar o en aplicación de alguno de los supuestos previstos en la normativa sobre derechos y deberes de los alumnos).

E) Los conflictos entre órganos constitucionales han sido 2:

La STC 34/2018, de 12 de abril, resuelve el conflicto planteado por el Gobierno de la Nación frente a los acuerdos de la Mesa del Congreso de los Diputados relativos a la suspensión del calendario de implantación de la Ley Orgánica 8/2013, de 9 de diciembre, para la mejora de la calidad educativa; y la STC 44/2016, de 26 de abril, resuelve el conflicto promovido por el Gobierno de la Nación frente a los acuerdos de la Mesa del Congreso de los Diputados respecto de una proposición de ley presentada por el Grupo Parlamentario Socialista sobre modificación del art. 42.1 del Estatuto de los Trabajadores para garantizar la igualdad en las condiciones laborales de los trabajadores subcontratados. Sobre el objeto de procesos de esta naturaleza, el Tribunal trae a colación las dos únicas decisiones en las que ha examinado esta cuestión: las SSTC 45/1986, de 17 de abril, y 234/2000, de 3 de octubre. A la luz de esta última doctrina constitucional, el Tribunal confirma que los acuerdos de la Mesa del Congreso impugnados por el Gobierno se acomodan al objeto del conflicto entre órganos constitucionales. Al igual que sucediera en el asunto decidido en la STC 234/2000, la Mesa de la Cámara no ha reivindicado para sí la potestad contenida en el art.134.6 CE, sino que la controversia se refiere al menoscabo de la competencia del Gobierno. Acotado el objeto, identifica la cuestión a resolver en este proceso, esto es, si la Mesa del Congreso ha producido un menoscabo de una competencia exclusiva del Gobierno, impidiendo ilegítimamente el ejercicio de la potestad que le atribuye el art.134.6 CE. De este modo, el Tribunal aborda una cuestión novedosa: la interpretación de dicho precepto constitucional en el marco de un conflicto entre órganos constitucionales.

El Tribunal sostiene que para resolver el conflicto resulta necesario precisar los contornos de la potestad del art.134.6 CE partiendo de la doctrina sobre el reparto de competencias presupuestarias entre el poder ejecutivo y el legislativo que se deriva del art.134 CE. De este modo, y tras repasar su doctrina sobre la función de la Ley de Presupuestos y el papel preponderante que el Gobierno, el Tribunal concluye que la apreciación de la Mesa de la Cámara, al considerar que la motivación del Gobierno resultó insuficiente para verificar la efectiva conexión de la medida con los ingresos y los gastos públicos, no menoscabó la competencia del ejecutivo en este caso. 
El art. 134.6 CE contiene una prerrogativa del Ejecutivo que tiene, como presupuesto habilitante, la vinculación estricta a la norma presupuestaria, que debe por ello verse afectada. Teniendo en cuenta, como ya se ha señalado, que cualquier iniciativa o proposición de ley es susceptible de suponer un incremento de gasto o una disminución de ingresos, el Gobierno debe justificar de forma explícita la adecuada conexión entre la medida que se propone y los ingresos y gastos presupuestarios. Esta conexión debe ser directa e inmediata, actual, por tanto, y no meramente hipotética. Debe además referirse al Presupuesto en particular, sin que pueda aceptarse un veto del Ejecutivo a proposiciones que, en el futuro, pudieran afectar a los ingresos y gastos públicos, pues ello supondría un ensanchamiento de la potestad de veto incompatible con el protagonismo que en materia legislativa otorga a las Cámaras la propia Constitución (art.66 CE) (FJ 8).

El fallo en ambos conflictos es desestimatorio.

F) Las Sentencias dictadas en recursos de amparo son 22:

De los recursos de amparo resueltos, 17 han sido estimados y dos parcialmente estimados, de los cuales 11 han tenido carácter devolutivo. Dos fueron desestimados y uno inadmitido.

La STC 38/2018, de 23 de abril, inadmite el recurso planteado al entender que la STS recurrida cumplía con todas las garantías exigibles con respecto al art. $24 \mathrm{CE}$, en particular en lo relativo a la motivación y a la razonabilidad de la resolución, sin que el Tribunal Constitucional pueda actuar como tercera instancia para contemplar otras interpretaciones posibles.

La STC 3/2018, de 22 de enero, analiza una vulneración por razón de edad y discapacidad, debido a la denegación de asistencia médica necesaria por discapacidad psíquica (tratamiento de servicio residencial) que se adopta sin valoración médica, atendiendo solo al requisito de edad previsto en la norma, en la que no se recoge justificación alguna de esa exclusión (que tampoco se ofreció en el procedimiento en el que se desestimó la solicitud), cuando además existían normas de mayor rango y fecha posterior que podían haber sido aplicadas evitando esa discriminación. Se infringe asimismo la exigencia de «ajustes razonables» prevista en la Convención de la ONU sobre los Derechos de las Personas con Discapacidad de 13 de diciembre de 2006, que pasaban por asegurar la prestación del servicio asistencial adaptado a las necesidades de la discapacidad padecida. Por estos motivos el fallo es estimatorio.

La STC 20/2018, de 5 de marzo, estima una vulneración de los derechos a la igualdad y del derecho de acceso a los medios públicos de comunicación 
social en relación con la libertad de sindicación. La Mesa de la Asamblea de Madrid excluye al sindicato recurrente del proceso de proposición de candidaturas para formar el Consejo de Administración de la radio televisión autonómica, a pesar de que el recurrente reúne los requisitos establecidos, sin que tal decisión contenga motivación alguna. Dicha motivación es especialmente necesaria, como ya ha indicado el Tribunal, cuando se trata de actos parlamentarios con efectos ad extra, como es el caso.

La STC 21/2018, de 5 de marzo, estima una vulneración del derecho a la libertad personal como consecuencia de no haber sido informado el recurrente de modo suficiente sobre las razones de su detención gubernativa de naturaleza penal ni habérsele permitido el acceso a los elementos de las actuaciones que eran esenciales para impugnar su legalidad. El TC desestima la pretensión relativa al 17.4 CE por no haber interpuesto frente a la resolución de no incoar el procedimiento de habeas corpus el imperativo incidente de nulidad de actuaciones. La especial trascendencia constitucional la cifra en la ausencia de doctrina específica del TC sobre el alcance del derecho a conocer las razones de la detención policial y de acceso a las actuaciones durante la detención tras la reforma de la Ley de Enjuiciamiento Criminal, operada por las leyes orgánicas 5/2015, de 27 de abril, y 13/2015, de 5 de octubre.

La STC 4/2018, de 22 de enero, otorga el recurso de amparo promovido por el Grupo Parlamentario Podemos en el Parlamento de Canarias en relación con los acuerdos de las mesas de la Comisión competente y del Parlamento que inadmitieron sus enmiendas al articulado presentadas a una proposición de ley. Para analizar el problema planteado el Tribunal trae a colación su doctrina general sobre el art. 23 CE (STC 76/2017, FJ 13), la jurisprudencia constitucional sobre el derecho de enmienda (SSTC 119/2011, FJ 9 y 139/2017, FJ 5) y sobre la función de calificación de las Mesas (STC 76/2017, FJ 3). Sobre el derecho de enmienda, recuerda que forma parte del contenido del ius in officium de los parlamentarios y cumple la relevante función de garantizar la participación e intervención de los diputados y de los grupos parlamentarios en el proceso de elaboración de la ley y, en último término, en la configuración del texto legislativo, contribuyendo de este modo a la formación de la voluntad de la Cámara (STC 139/2017, FJ 5). Asimismo, reconoce que el ejercicio del derecho de enmienda no está exento de límites (STC 204/2011, FJ 4), como los derivados de la propia definición que los reglamentos parlamentarios realizan de las enmiendas a la totalidad y al articulado, y de la exigencia general de conexión u homogeneidad entre las enmiendas y los textos a enmendar (SSTC 119/2011, FJ 6; 136/2011, FJ 7, y 234/2012, FJ 4).

El Tribunal procede a realizar un control externo de la actuación de los órganos parlamentarios involucrados y constata que los acuerdos impugnados 
inadmitieron a trámite las enmiendas presentadas por el grupo parlamentario recurrente partieron de un presupuesto de hecho erróneo: conceptuaron como una enmienda encubierta a la totalidad el conjunto de enmiendas al articulado presentadas por el grupo recurrente. Lo cual condujo a que las Mesas adoptasen una decisión que no cumple con las exigencias de una motivación expresa, suficiente y adecuada exigida por la jurisprudencia constitucional, ni ofrece respuesta a la diferencia de trato dado a las enmiendas presentadas por el grupo parlamentario recurrente, frente al dispensado a las enmiendas presentadas por otros grupos parlamentarios.

Por todo ello, concluye que los acuerdos impugnados no han cumplido las exigencias de motivación expresa, suficiente y adecuada, en aplicación de las normas a las que está sujeta la Mesa en el ejercicio de su función de calificación y admisión de los escritos y documentos de índole parlamentaria (por todas, STC 23/2015, de 16 de febrero, FJ 8), y como consecuencia de ello han restringido el ius in offcium de los parlamentarios recurrentes.

La STC 10/2018, de 5 de febrero, y la STC 27/2018, de 5 de marzo, resuelven los recursos de amparo presentados por el Grupo Parlamentario Socialista del Parlamento de Cataluña contra los acuerdos de la Mesa de la Cámara que inadmiten la solicitud de dictamen del Consejo de Garantías Estatutarias relativo a la conformidad de las leyes del referéndum de autodeterminación y de transitoriedad jurídica y fundacional de la república, respectivamente, a la Constitución y al Estatuto de Autonomía de Cataluña.

En primer lugar, la sentencia recuerda que los acuerdos impugnados formaron parte de la tramitación de las leyes del referéndum de autodeterminación y de transitoriedad jurídica y fundacional de la república, que fueron declaradas inconstitucionales y nulas por las STC 114/2017 y STC 124/2017, respectivamente. Asimismo, señala que los AATC 123/2017 y 124/2017 estimaron los incidentes de ejecución de las sentencias anteriores y declaró la nulidad, tanto de los acuerdos de la Mesa del Parlamento de Cataluña de admisión a trámite por el procedimiento de urgencia extraordinaria de ambas proposiciones de ley como de los acuerdos del Pleno por los que se incluyó en el orden del día el debate y votación de las mismas, suprimiendo algunos trámites esenciales del procedimiento legislativo.

Tras fijar el marco jurisprudencial y normativo, constituido por dichas resoluciones junto al Reglamento del Parlamento de Cataluña, el Estatuto de Autonomía y la Ley del Consejo de Garantías Estatutarias, y traer a colación la doctrina constitucional sobre el derecho invocado (art.23.2 CE), el Tribunal constata que la supresión del trámite parlamentario, consistente en solicitar dictamen al Consejo de Garantías Estatutarias sobre la adecuación de las proposiciones de ley a la Constitución y el Estatuto de Autonomía, se produjo 
fuera de toda previsión del Reglamento Parlamentario y del resto del ordenamiento. Por ello, siguiendo lo decidido en las SSTC 114 y 124/2017, concluye que la supresión de la posibilidad de pedir dicho dictamen afectó a una facultad perteneciente al núcleo de la función representativa parlamentaria que se integraba en el ius in officium de los parlamentarios catalanes (SSTC 10/2018, FJ 5; y 27/2018, FJ 5).

Por último, reitera que es

función primordial de toda asamblea parlamentaria, también por tanto del Parlamento de Cataluña (arts. 152.1 CE y 55.1 EAC), representar a la ciudadanía; función que sólo se cumple si los elegidos por el cuerpo electoral para realizarla se atienen a los procedimientos que el ordenamiento dispone y a las reglas jurídicas que, integradas sobre todo en los reglamentos de las Cámaras, aseguran el ejercicio de los derechos y facultades de los parlamentarios, así como la participación no discriminatoria de todos sus representantes. Se asegura, con ello, el necesario respeto de las minorías, sin el cual el principio de mayoría para la adopción final de las decisiones, igualmente irrenunciable, pondría en riesgo su legitimidad. La democracia parlamentaria no se agota, ciertamente, en formas y procedimientos, pero el respeto a unas y otros está entre sus presupuestos inexcusables -STC 109/2016, FJ 5- (SSTC 10 y 27/2018, FJ 5).

En la STC (Pleno) 46/2018, de 26 de abril, la cuestión de fondo suscitada consiste en determinar si la Mesa de la Cámara, al admitir a trámite la solicitud de comparecencia del presidente de la Generalitat ante el Pleno de la Cámara «para valorar los resultados del referéndum, y sus efectos, de acuerdo con el art. 4 de la Ley del Referéndum de autodeterminación», vulneró el ius in officium de los diputados recurrentes. De este modo, para analizar el presente asunto el Tribunal analiza si forma parte del ius in officium de los parlamentarios el derecho a que no se tramiten iniciativas que incurran en graves infracciones constitucionales o que su tramitación conlleve incumplir el deber de respetar las resoluciones del Tribunal Constitucional. El Tribunal concluye que la Mesa del Parlamento de Cataluña, al admitir la iniciativa parlamentaria, incumplió (i) el específico deber de respetar la suspensión declarada por sendas providencias de 7 de septiembre de 2017 de la eficacia de la Ley denominada "del referéndum de autodeterminación" y la del Decreto de convocatoria de ese «referéndum» y (ii) el deber de no realizar actuaciones que traigan causa de resoluciones o normas declaradas inconstitucionales y nulas por este Tribunal. En consecuencia, la decisión de la Mesa Cámara constituye un manifiesto incumplimiento de su deber de respetar lo resuelto por este Tribunal (arts. 9.1 CE y 87.1 LOTC). 
Además, considera que el incumplimiento de este deber determina la lesión del ius in officium de los parlamentarios recurrentes, ya que «la admisión de la iniciativa impide que, en relación con ese procedimiento parlamentario, puedan ejercer legítimamente sus funciones representativas, pues, en tales circunstancias, el ejercicio de su cargo conllevaría no acatar lo resuelto por el Tribunal Constitucional e incurrir, por tanto, en un grave ilícito constitucional» (FJ 7). Por último, la sentencia considera que la propuesta admitida a trámite conlleva la pretensión de alterar la condición y posición institucional de la Cámara al atribuirse "potestades propias del poder constituyente, situándose de este modo fuera del ordenamiento constitucional, lo que determina que también queden extramuros de la Constitución los derechos fundamentales de los parlamentarios» (FJ 8).

La STC 47/2018, de 26 de abril, estima el recurso de amparo presentado por varios diputados del Parlamento de Cataluña contra el Acuerdo de la Mesa de la Cámara, que califica y admite a trámite las propuestas de resolución denominadas «Declaración de los representantes de Cataluña»y «Proceso constituyente», por vulneración de su derecho a ejercer las funciones representativas (art.23.2 CE). En el presente caso, y a diferencia de los supuestos enjuiciados en las SSTC 107, 108 y 109/2016, existe una obligación de la Mesa de inadmitir a trámite las iniciativas que se fundamenten en una resolución suspendida o declarada inconstitucional por el Tribunal Constitucional. Efectivamente, ambas propuestas se apoyaban y buscaban dar efectividad a dos leyes, una declarada inconstitucional y nula por la STC 114/2017, y otra suspendida en su vigencia y aplicación por el Tribunal Constitucional. Asimismo, al amparo de lo dispuesto en el art.87.1 LOTC, este había advertido a la Presidencia e integrantes de la Mesa del Parlamento de Cataluña su deber de impedir o paralizar cualquier iniciativa que supusiera ignorar o eludir las resoluciones. Por ello, existe un deber (no mera facultad) de control material de las propuestas o proposiciones de los grupos parlamentarios derivado de un mandato jurisprudencial que impone dicha obligación (FJ 5). La Mesa tenía ante sí no solo la constatación de la manifiesta inconstitucionalidad, sino también el inequívoco deber de impedir o paralizar las iniciativas presentadas.

La sentencia considera que las resoluciones impugnadas, al desatender las advertencias de los servicios jurídicos del Parlamento y los requerimientos de las resoluciones del Tribunal Constitucional, afectó a la situación parlamentaria de los recurrentes,

que se vieron en la tesitura obligatoria de tener que optar entre atender al mandato representativo de los ciudadanos por los que habían resultado elegidos, para lo cual tendrían que asistir a un Pleno en el que se iban a debatir, contra 
la prohibición expresa de este Tribunal, determinadas propuestas de resolución manifiestamente inconstitucionales; o no asistir a la sesión plenaria, lo que les llevaría tener que ausentarse del Pleno, para desvincularse de aquellas iniciativas prohibidas, desatendiendo de ese modo sus funciones como tales parlamentarios electos.

Tal obligación de tener que optar entre ambas posibilidades

implicaba una grave afectación del ius in officium de los diputados recurrentes, pues éstos habrían de debatirse entre tomar parte en una sesión parlamentaria con un contenido claramente contraventor de la Constitución y de la legalidad, dando una apariencia de normalidad parlamentaria y democrática a un acto que no la tenía, o ausentarse del mismo y no participar en el debate y votación, teniendo que renunciar obligatoriamente a sus funciones más características, como parlamentarios representantes de los ciudadanos que los eligieron (FJ 6).

En consecuencia, el Tribunal concluye que los acuerdos impugnados vulneraron el contenido esencial del ius in officium de los diputados.

La STC 12/2018, de 8 de febrero, estima una vulneración del principio de legalidad sancionadora. El recurrente informó a los alumnos y sus padres de que pensaba secundar una huelga de enseñanza convocada y la Consejería de Educación le sanciona por el incumplimiento de los deberes de los funcionarios públicos. Aunque alega la vulneración de los derechos a la libertad de expresión, a la huelga, a la tutela judicial efectiva y a la legalidad sancionadora, el Tribunal se centra en este último. La conducta del profesor no puede incluirse en ninguno de los tipos sancionadores aplicados, pues apenas utilizó tiempo lectivo para realizar esta comunicación y del expediente no puede deducirse que se produjese un adoctrinamiento de los niños. Por tanto, no se han incumplido los deberes de los funcionarios y las resoluciones han vulnerado el derecho a la legalidad sancionadora del recurrente, no entrando en los otros derechos alegados.

Las vulneraciones del art. 24 de la Constitución se clasifican de la siguiente forma:

a) Actos de comunicación procesal: STC 5/2018, de 22 de enero; 38/2017, de 25 de abril. En ambas reitera previa doctrina sobre esta cuestión, no obstante, incumplida por los órganos jurisdiccionales ordinarios.

b) Acceso a la justicia: STC 6/2018, de 22 de enero: el Tribunal se remite a su jurisprudencia previa en cuanto al contenido del art. 24.1 CE: 
acceso a la jurisdicción, principio pro actione, imposibilidad de clausurar un procedimiento por defectos que puedan ser subsanados (STC 19/1981), dimensión esta última no tenida en cuenta por el órgano judicial, al no haber concedido la posibilidad de subsanación y no haber considerado la documentación aportada por la parte demandante (cuya suficiencia en todo caso no valora el Tribunal Constitucional). Se analiza a renglón seguido si el error judicial detectado ostenta relevancia constitucional, siguiendo para ello el canon establecido en las SSTC 167/2014 y 186/2015: error patente, que haya producido efectos negativos en la esfera jurídica del ciudadano, siempre que se trate de un error verificable, de forma incontrovertible, a partir de las actuaciones judiciales y siendo determinante de la decisión adoptada, constituyendo soporte único o básico de la resolución. Acreditada la concurrencia de los elementos señalados, se concluye la estimación del recurso.

c) Tutela judicial efectiva y legalidad sancionadora: STC 9/2018, de 5 de febrero: el Tribunal reproduce su doctrina previa sobre la aplicabilidad de los principios sustantivos del art. 25. 1 CE al derecho administrativo sancionador (SSTC 18/1981 y 54/2015), siempre que la traslación de dichas garantías resulte compatible con la naturaleza del procedimiento. Comienza su razonamiento determinando la norma aplicable, es decir, el Estatuto Orgánico del Ministerio Fiscal (régimen disciplinario) y el Reglamento Orgánico del Estatuto del Ministerio Fiscal de 1969 (parcialmente vigente en la dimensión procedimental), rechazando en consecuencia la vulneración del derecho a un proceso con todas las garantías (art. 24.2 CE). A continuación, el Tribunal pasa a valorar de manera individualizada las denuncias alegadas en atención a diversas dimensiones del derecho a la tutela judicial efectiva: caducidad del expediente (cuestión de legalidad ordinaria que no corresponde al Tribunal), ausencia del Ministerio Fiscal en el procedimiento (cuestión de legalidad ordinaria, no se acredita lesión de derecho fundamental), debida separación entre el órgano que instruye y el que dicta la sanción (hubo separación de funciones, no tiene relevancia constitucional, y el Tribunal no puede entrar a valorar la cuestión al no haberse permitido al órgano sancionador pronunciarse previamente sobre la pretendida vulneración), nombramiento irregular del instructor (la recurrente no hizo valer el incidente de recusación en su momento, se desestima la pretensión). Finaliza el Tribunal desestimando la alegada violación de la 
vertiente material del principio de legalidad penal (art. 25. 1 CE). Procede en consecuencia a desestimar el recurso.

STC 25/2018, de 5 de marzo, se analizan los derechos enunciados en relación con apreciación de la prescripción de delito: falta de conexión que funda el rechazo de la prescripción a partir de los hechos probados, por lo que se considera irrazonable la resolución por falta de motivación, lo que da lugar a su estimación. El Sr. Xiol Ríos firma un voto particular discrepante, pues entiende que sí existía base fáctica para ese razonamiento.

d) Motivación: STC 22/2018, de 5 de marzo, que remite en buena parte de su argumentación a las SSTC 232/2015 y 135/2017, en torno la exigencia de motivación de las resoluciones judiciales, en este caso con respecto a la inaplicación de una directiva europea y a la no presentación de una cuestión prejudicial; formulan un voto particular concurrente el Sr. Conde-Pumpido y la Sra. Balaguer.

STC 23/2018, de 5 de marzo, en la cual el TC estima el amparo por haber omitido el órgano judicial pronunciarse sobre una de las pretensiones del demandante, alegando el carácter exclusivamente revisor de la jurisdicción contencioso-administrativa.

e) Derecho a la defensa y a la asistencia letrada: STC 24/2018, de 5 de marzo, en la que se justifica la especial trascendencia constitucional en la necesidad de aclarar la doctrina sobre el alcance del principio de sujeción del acusado al procedimiento, en particular desde la STC 91/00, que introduce el juicio de proporcionalidad como criterio de control de las consecuencias procesales atribuidas a la incomparecencia voluntaria del acusado en el proceso penal, según la jurisprudencia del TEDH sobre el derecho de defensa en el marco del derecho a un proceso equitativo (art. 6.3 CEDH). A la luz de dicha STC 91/2000 y de las posteriores 198/2003 y 132/2011, el Tribunal analiza las circunstancias en las que el demandante considera vulnerado su derecho por denegarle el órgano judicial la posibilidad de tenerlo por comparecido en la persona de su procurador, una vez que conoce la existencia de una orden de busca y captura contra él. Llega a la conclusión de que las resoluciones judiciales no satisfacen el juicio de necesidad, por cuanto omiten toda consideración (en cualquier sentido) de los datos aportados en el caso concreto: el demandante se encontraba fuera de Espańa, pero aportaba su domicilio y la voluntad de declarar por videoconferencia, pues por razones de salud no podía acudir ante el órgano judicial español (con cita de STEDH). 
f) Intangibilidad: STC 35/2018, de 23 de abril: vulneración del derecho a la tutela judicial efectiva (art. 24.1 CE) en su vertiente de derecho a la intangibilidad de las resoluciones judiciales firmes, derecho al proceso con todas las garantías (art. 24. 2 CE) e igualdad en la aplicación de la ley (art. $14 \mathrm{CE}$ ). Se alega que tales derechos fueron transgredidos en la medida en que la sentencia impugnada funda su decisión de no continuar con la ejecución de una previa resolución de primera instancia (no recurrida en apelación por ninguna de las partes) por entender que constituye un abuso de derecho respecto de la reclamación de las pensiones devengadas con anterioridad a la sentencia que declara la extinción de la obligación alimenticia. El Tribunal llega a la conclusión de que dicho auto ha frustrado la ejecución de la sentencia en sus propios términos mediante la mutación del fallo llevada a cabo durante el propio expediente de ejecución.

g) Derecho a un proceso con todas las garantías y a la defensa: SSTC 36 y 37/2018, ambas de 23 de abril, que traen causa de la condena a los recurrentes, absueltos en la instancia, por un cambio de valoración de pruebas personales (el grado de conocimiento del ilícito) sin haber dado audiencia a los recurrentes.

La STC 26/2018, de 5 de marzo, en la que, tras un proceso penal iniciado por un conflicto interno abierto entre militantes del partido político UPyD (Rodrigo Tena, el recurrente, denunció el acceso indebido y posterior revelación del contenido de los mensajes de correo electrónico intercambiados en una cuenta facilitada por el partido político), el órgano judicial acordó el sobreseimiento provisional de las actuaciones. El TC sostiene que el objeto del recurso de amparo debe de ser «comprobar si la argumentación que soporta la conclusión de sobreseimiento provisional de las actuaciones seguidas en vía penal responde al canon constitucionalmente exigible en estos casos", y que si bien ha de tener en cuenta lo pertinente al derecho a la tutela judicial efectiva en clave de acceso a la jurisdicción y como tutela de derechos fundamentales sustantivos como el derecho a la intimidad (art. 18.1 CE), al secreto de las comunicaciones (art. 18.3 CE) y el derecho de asociación (art. $22 \mathrm{CE}$ ), en el caso nada puede objetarse al modo de proceder del órgano penal al decidir el archivo de las actuaciones. El fallo es desestimatorio; cuenta con un voto particular discrepante firmado por los magistrados Conde-Pumpido y Balaguer.

Las resoluciones judiciales recurridas, según el órgano que las dictó, han sido: 


\begin{tabular}{lccc}
\hline \multicolumn{1}{c}{ Órgano } & Sentencia & Auto & $\begin{array}{c}\text { Decreto de } \\
\text { Secretaría }\end{array}$ \\
\hline Tribunal Supremo & 2 & 2 & \\
Audiencia Nacional & & 1 & \\
Tribunal Superior de Justicia & 2 & & \\
Audiencia Provincial & & 2 & \\
Juzgado de 1.a Instancia & & 2 & \\
Juzgado de Instrucción & & 1 & \\
Juzgado de lo Contencioso-Administrativo & 1 & & \\
\hline
\end{tabular}

En el período se han pronunciado 28 votos particulares, alguno de ellos firmado por más de un magistrado y otros a los que se adhieren otros magistrados; los magistrados firmantes han sido:

- Balaguer Callejón: 6.

- Conde-Pumpido Tourón: 5.

- González-Trevijano Sánchez: 2.

- Narváez Rodríguez: 4.

- Roca Trías: 1.

- Valdés Dal-Ré: 6.

- Xiol Ríos: 4.

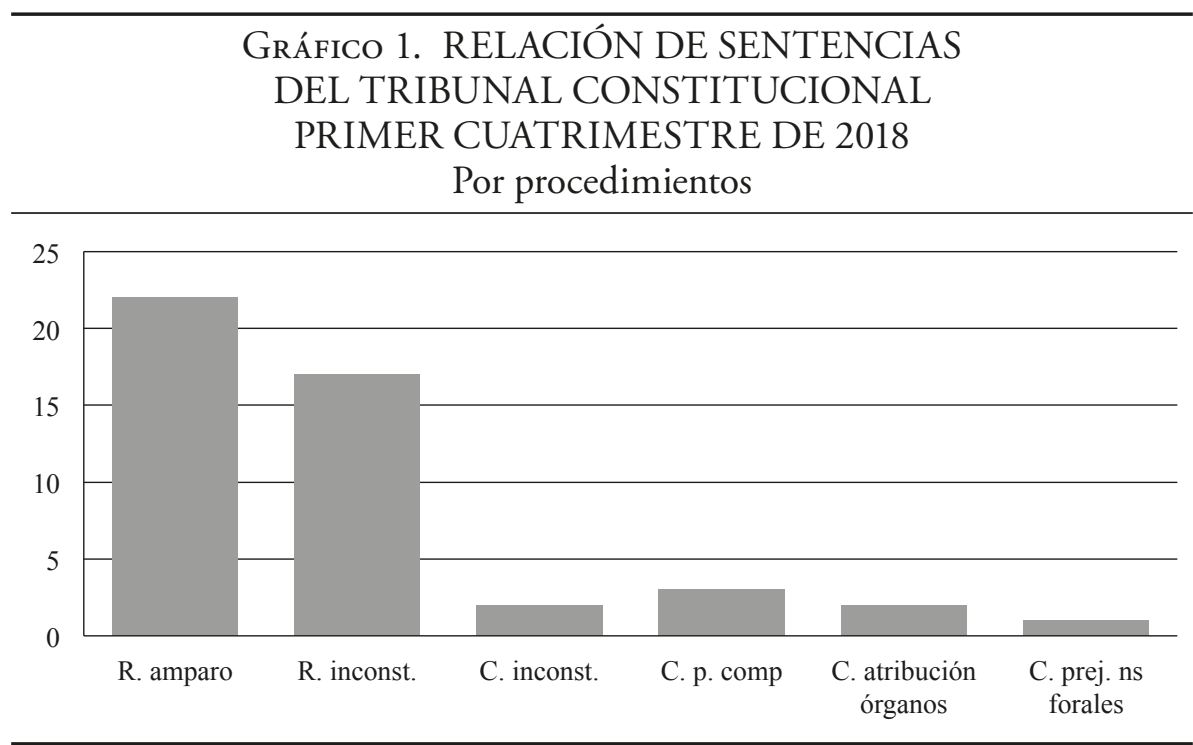




\section{GráfICo 2. RECURSOS DE AMPARO. SEGÚN EL CONTENIDO PRIMER CUATRIMESTRE DE 2018}

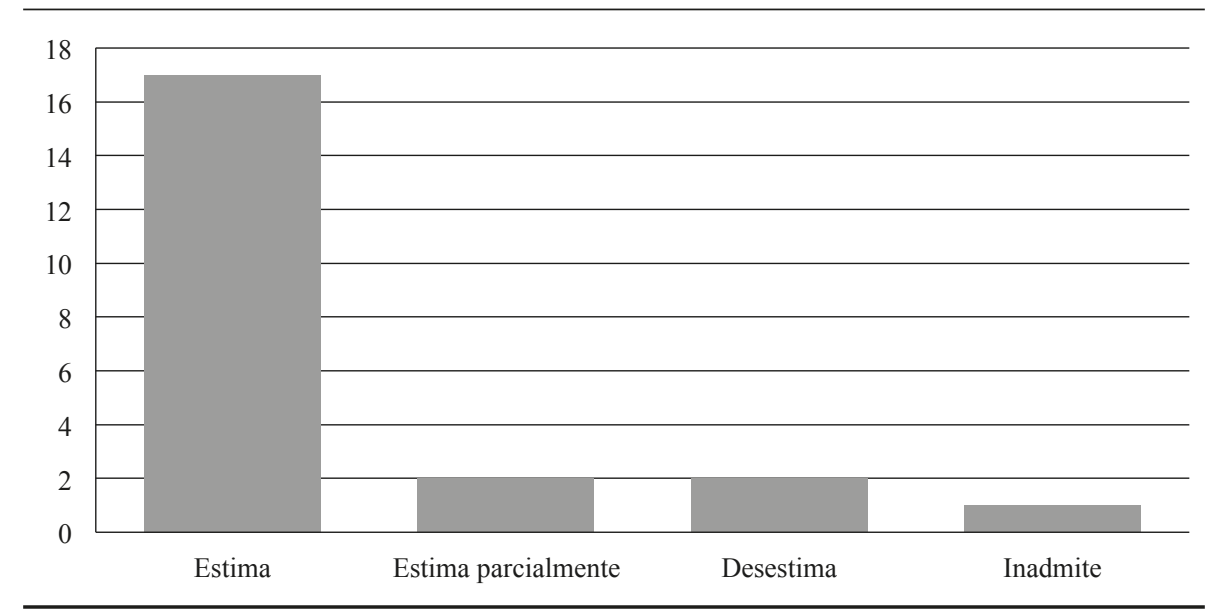

GrÁFICO 3. RECURSO DE AMPARO.

DERECHO FUNDAMENTAL ALEGADO.

PRIMER CUATRIMESTRE DE 2018

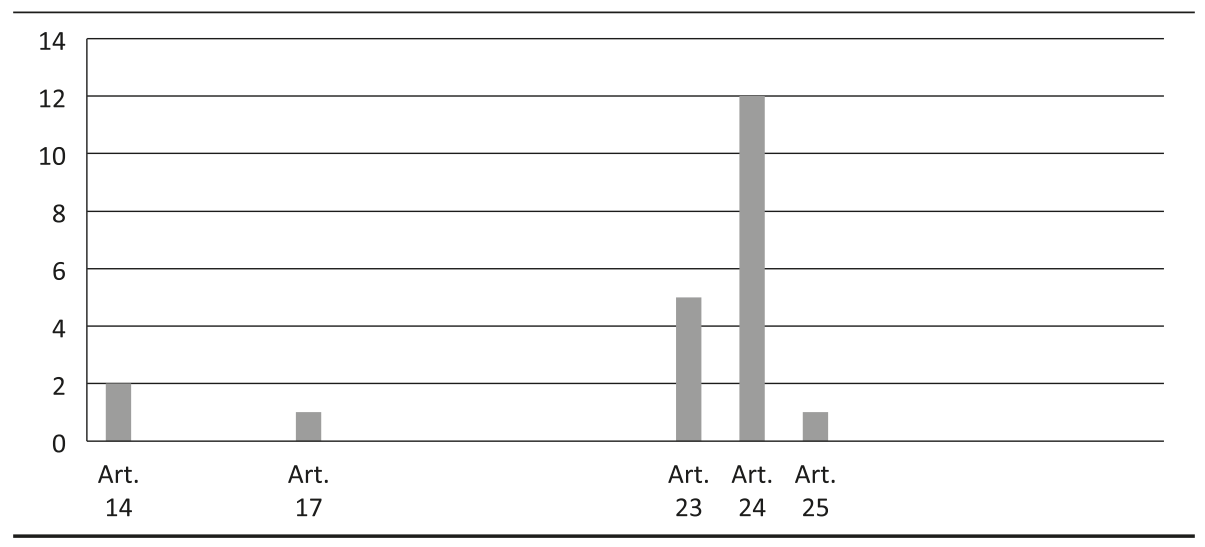


GrÁFICO 4. RECURSOS DE AMPARO. ÓRGANO JUDICIAL QUE DICTA LA RESOLUCIÓN RECURRIDA. PRIMER CUATRIMESTRE DE 2018

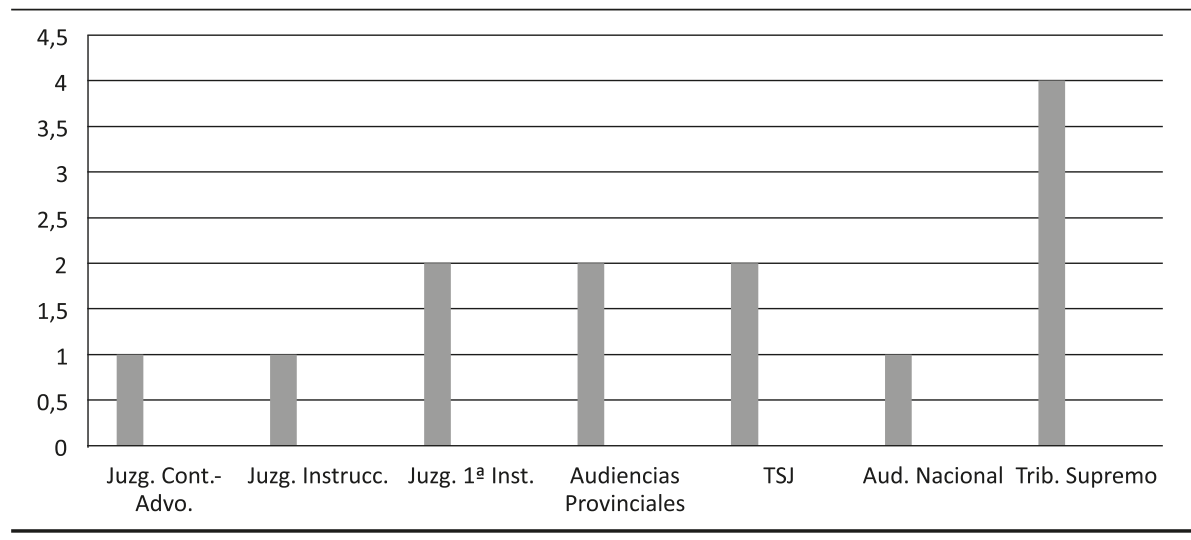

GrÁFICO 5. RECURSOS DE AMPARO.

TIPO DE RESOLUCIÓN RECURRIDA.

PRIMER CUATRIMESTRE DE 2018

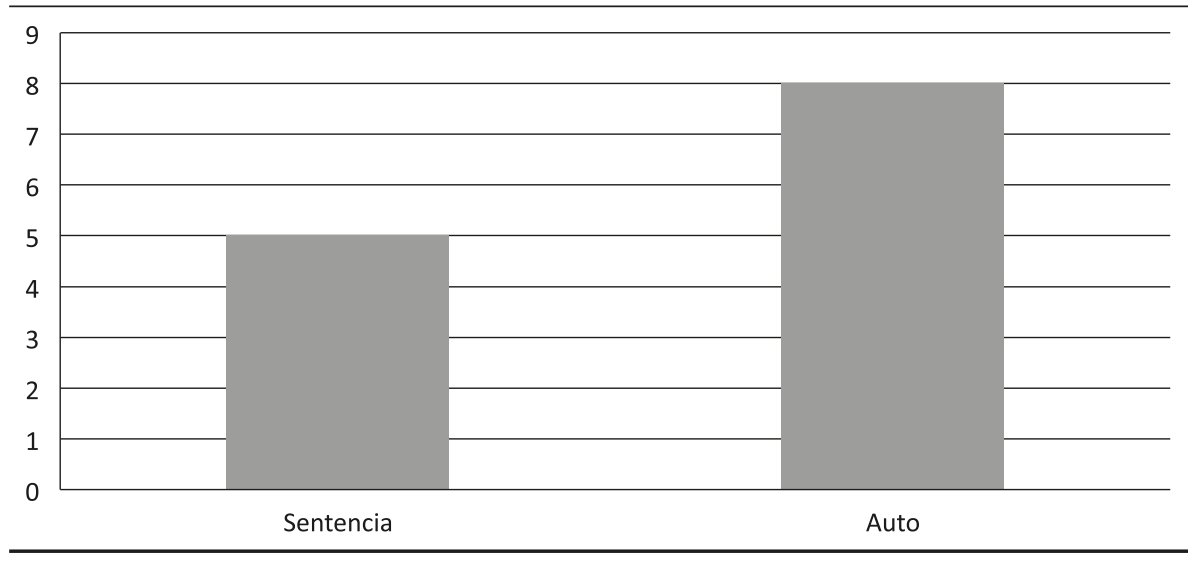

